\title{
Transporte aéreo e passageiros com deficiência auditiva: barreiras e facilitadores
}

\section{Air transport and passengers with hearing impairments: barriers and facilitators}

\author{
Talita Naiara Rossi da Silva ${ }^{1}$, Letícia Adelia Ribeiro ${ }^{2}$, Gabriela Almeida Silvestrini ${ }^{3}$, \\ Heloisa Giangrossi Machado Vidotti ${ }^{4}$, Julia Pierre Figueiredo ${ }^{5}$, Nilton Luiz \\ Menegon $^{6}$
}

http://dx.doi.org/10.11606/issn.2238-6149.v31i1-3p69-77

Silva TNR, Ribeiro LA, Silvestrini GA, Vidotti HGM, Figueiredo JP, Menegon NL. Transporte aéreo e passageiros com deficiência auditiva: barreiras e facilitadores. Rev Ter Ocup Univ São Paulo. 2020 jan.-dez.;31(1-3):69-77.

RESUMO: Este estudo teve como objetivo compreender as barreiras e facilitadores para a participação das pessoas com deficiência auditiva em viagens aéreas. Fundamentou-se na abordagem da ergonomia da atividade. Os dados foram coletados por meio de questionário, observações diretas durante as viagens e entrevistas de autoconfrontação com passageiros com deficiência auditiva. Constatou-se a existência de barreiras relacionadas a fatores sociais, como comunicação, e ambientais, como sinalização nos aeroportos. Entre os facilitadores das viagens destacaram-se a comunicação com trabalhadores que têm conhecimento da língua de sinais e legendas nos conteúdos de entretenimento a bordo. Este estudo espera dar visibilidade às experiências de viagens de passageiros com deficiência auditiva e, a partir disso, contribuir para a melhoria das condições e procedimentos do transporte aéreo e orientar a formação de pessoal visando prestar serviços adequados aos diversos passageiros.

DESCRITORES: Pessoas com deficiência auditiva; Viagem aérea; Ergonomia.
Silva TNR, Ribeiro LA, Silvestrini GA, Vidotti HGM, Figueiredo JP, Menegon NL. Air transport and passengers with hearing impairments: barriers and facilitators. Rev Ter Ocup Univ São Paulo. 2020 Jan-Dec;31(1-3):69-77.

ABSTRACT: This study aims to understand the barriers and facilitators to the participation of persons with hearing disability in air travel. This study was based on the assumptions of activity-centered ergonomics. Data was collected by means of a questionnaire, direct observations during trips and selfconfrontation interviews with passengers with hearing disability. The study findings include barriers related to social factors, such as communication, and environmental factors, such as airport signage. Air travel facilitators included communication in sign language with workers and closed-captioned in-flight entertainment for passengers. This study hopes to give visibility to travel experiences of passengers with hearing disability, and from that to contribute to the improvement of air transport conditions and procedures and to guide staff training aiming to provide adequate services to diverse passengers.

KEYWORDS: Persons with hearing impairments; Air travel; Ergonomics.

1. Docente. Departamento de Fisioterapia, Fonoaudiologia e Terapia Ocupacional, Faculdade de Medicina, Universidade de São Paulo. ORCID: 0000-0002-8768-186X. Email: talitarossi@usp.br

2. Graduanda em Terapia Ocupacional. Departamento de Terapia Ocupacional, Universidade Federal de Minas Gerais. ORCID: 0000-0002-4168-5320. Email: leticia.adribeiro@gmail.com

3. Graduanda em Terapia Ocupacional. Departamento de Terapia Ocupacional, Universidade Federal de Minas Gerais. ORCID: 0000-0001-8790-5686. Email: silvestrini.gabriela@gmail.com

4. Pós-doutoranda em Engenharia de Produção. Departamento de Engenharia de Produção, Universidade Federal de São Carlos. ORCID: 0000-0002-7606-3695. Email: helogm@yahoo.com.br

5. Mestranda em Engenharia de Produção. Departamento de Engenharia de Produção, Universidade Federal de São Carlos. ORCID: 0000-0003-3429-1448. Email: juliapierrefig@gmail.com

6. Docente. Departamento de Engenharia de Produção, Universidade Federal de São Carlos. ORCID: 0000-0001-9202-7929. Email: menegon@dep.ufscar.br

Endereço para correspondência: Talita Naiara Rossi da Silva. Rua Cipotânea, 51 - Cidade Universitária - São Paulo - SP - Brazil - CEP 05360-000.

Telefone: +55 113091 8436. Email: talitarossi@usp.br 


\section{INTRODUÇÃO}

$\mathrm{D}_{\mathrm{s}}^{\mathrm{e}}$ acordo com as estimativas da Organização Mundial de Saúde ${ }^{1}$ cerca de um bilhão de pessoas possui alguma deficiência. No Brasil, o Censo Demográfico de 2010 do Instituto Brasileiro de Geografia e Estatísticas (IBGE) ${ }^{2}$ apontou que $23,9 \%$ dos brasileiros têm algum tipo de deficiência.

A partir da perspectiva do modelo biopsicossocial a deficiência é definida como uma experiência multidimensional. Essa perspectiva modificou o conceito de deficiência ao compreender que há um fator biológico associado, mas que são os fatores sociais e atitudinais que caracterizam a experiência de incapacidade. Dessa forma, busca-se retirar a lógica que culpabiliza o indivíduo por sua segregação e salienta-se a necessidade de ações políticas frente a opressão ${ }^{3 .}$

Considerando essas mudanças no entendimento da deficiência, a Organização das Nações Unidas $(\mathrm{ONU})^{4}$, propôs uma nova definição na Convenção sobre os Direitos das Pessoas com Deficiência que salienta o caráter interacional da experiência de incapacidade e desvantagens sociais e incentiva a reflexão sobre os direitos dessas pessoas que necessitam de um ambiente que favoreça seu desempenho ocupacional e a participação na sociedade. Assim, compreende-se que disponibilizar ambientes acessíveis a todos é a conquista e afirmação de um direito.

Apesar das mudanças de perspectivas no entendimento da deficiência e dos progressos nos direitos estabelecidos nos documentos internacionais ${ }^{4} \mathrm{e} \mathrm{nacionais}^{5,6}$ nas últimas décadas, as pessoas com deficiência ainda são alvo de discriminação, diferenciações que as inferiorizam ou de homogeneizações que as anulam enquanto indivíduos singulares ${ }^{7}$. Para exemplificar essa situação diversos estudos evidenciaram barreiras no transporte aéreo que originam restrições à participação das pessoas com deficiência ${ }^{8-12}$.

Freeman e Selmi ${ }^{13}$ compararam as necessidades dos turistas com deficiência na França e no Canadá e mostraram que a ausência de língua de sinais é a principal barreira para a compreensão de instruções em caso de emergência e para comunicar-se com funcionários. As mesmas barreiras foram encontradas em estudos com passageiros brasileiros ${ }^{11,14,15}$. Esses estudos destacaram as dificuldades relacionadas às informações com ausência de conteúdos visuais associados ou transmitidas na língua de sinais na aeronave. Tais situações ocasionam, por exemplo, a não percepção dos avisos de voos realizados por áudio e a não compreensão dos procedimentos de segurança em voo. Outro estudo com passageiros brasileiros destacou que as barreiras relativas à informação dificultam a orientação dos passageiros com deficiência auditiva no terminal aeroportuário ${ }^{16}$.
Além disso, os participantes dos estudos de Silva ${ }^{15}$ e Silva et al $^{11}$ relataram dificuldades no uso de sistema de entretenimento a bordo. Esses resultados corroboram o estudo de Eghtesadi et al. ${ }^{17}$ que analisaram a experiência dos passageiros com deficiência visual e auditiva no transporte aéreo com foco no entretenimento em voo. O estudo descreveu o sistema de entretenimento como um recurso que durante a viagem aérea oferece filmes, músicas, programas variados e atualizações de voo, por exemplo, horário de chegada, conexões e mudança de portão, mas que é inacessível aos passageiros com deficiência auditiva e/ou visual.

Diante do exposto, esse estudo teve como objetivo compreender as barreiras e os facilitadores para a participação das pessoas com deficiência auditiva nas viagens aéreas.

\section{MÉTODO}

Esse estudo foi desenvolvido no âmbito de dois projetos realizados entre 2012 e 2017 por meio de um acordo de cooperação entre a Universidade Federal de São Carlos, a Embraer S/A e a Agência Nacional de Aviação Civil (ANAC), com a participação da Universidade Federal de Minas Gerais. Ambos os projetos foram aprovados pelo Comitê de Ética em Pesquisa envolvendo Seres Humanos (CAAE: 18017613.7.0000.5504; CAAE: 18017613.7.0000.5504). Todos os participantes assinaram o termo de consentimento livre e esclarecido e concordaram voluntariamente em participar do estudo.

Este estudo fundamentou-se na ergonomia da atividade ${ }^{18}$. Participaram desse estudo pessoas com deficiência auditiva. Considerando o enfoque qualitativo deste estudo, o número de participantes não foi definido a priori ${ }^{19}$. A coleta de dados foi realizada em uma feira internacional de reabilitação, inclusão e acessibilidade e a partir de um questionário online.

Foram realizadas viagens com pessoas com deficiência auditiva, maiores de 18 anos e independentes para realização de viagens aéreas foram realizadas. Esses participantes foram selecionados a partir dos contatos obtidos em projetos anteriores e junto à comunidade da Universidade Federal de Minas Gerais.

Foi utilizado um questionário com questões fechadas sobre dados sociodemográficos (idade, escolaridade, gênero, tipo de deficiência) e motivo e frequência de viagens. Questões abertas abordavam as experiências dos participantes no transporte aéreo, incluindo as dificuldades encontradas nas viagens considerando o aeroporto e as fases de embarque, voo e desembarque; estratégias utilizadas para lidar com essas dificuldades. Esse instrumento foi aplicado por meio de entrevista semiestruturada na feira e auto aplicado via questionário online. 
Silva TNR, et al. Transporte aéreo e passageiros com deficiência auditiva. Rev Ter Ocup Univ São Paulo. 2020 jan.-dez.;31(1-3):69-77.

Nas viagens aéreas os passageiros foram observados nas fases de pré-viagem, pré-voo, embarque e desembarque da aeronave, incluindo as condições e procedimentos relativos à acessibilidade em aeroportos e as dificuldades vivenciadas durante voos domésticos. Após as observações foram realizadas as entrevistas de autoconfrontação ${ }^{18}$. Um intérprete de LIBRAS acompanhou as viagens e auxiliou na comunicação com os passageiros surdos.

Os dados obtidos por meio do questionário foram inicialmente organizados em planilhas (MS Excel) e analisados separadamente, considerando-se as especificidades de cada contexto de coleta de dados e as variações nos procedimentos adotados. A partir da constatação da coerência entre os resultados esses foram unificados para análise. Dados de caraterização foram submetidos a análise estatística descritiva, enquanto os dados referentes às experiências de viagens e as entrevistas de auto confrontação foram analisados utilizando o Método de Análise do Conteúdo, modalidade de análise temática.

\section{RESULTADOS}

Responderam ao questionário na feira e online 25 pessoas com deficiência auditiva que tinham experiência prévia de viagem. $28 \%$ dos participantes reportaram ter perda auditiva bilateral profunda e $8 \%$ perda auditiva bilateral moderada. $20 \%$ dos participantes utilizavam algum equipamento assistivo auditivo. $52 \%$ eram mulheres. A maioria dos participantes tinham idade entre 30 e 39 anos (40\%) e entre 20 e 29 anos (36\%). Participantes viajavam por motivos relacionados ao lazer (44\%) e trabalho (24\%); menos de uma vez ao ano (44\%) ou uma ou duas vezes ao ano $(28 \%)$.

A Tabela 1 apresenta os participantes com deficiência auditiva que viajaram com os pesquisadores e os respectivos trechos de voo. Os participantes T2 e T3 se comunicavam por língua de sinais. Em relação a frequência de viagem, T1 viajavam de 1 a 2 vezes ao ano; T3 menos de uma vez ao ano e T2 viajou pela primeira vez ao participar do estudo.

Tabela 1 - Dados demográficos dos passageiros

\begin{tabular}{ccccccc}
\hline id & Sexo & Idade & Escolaridade & Tipo de deficiência & $\begin{array}{c}\text { Dispositivo } \\
\text { assistivo }\end{array}$ & Trecho de viagem/aeroporto \\
\hline P1 & Feminino & 21 & Superior incompleto & $\begin{array}{l}\text { Perda bilateral moderada } \\
\text { a severa }\end{array}$ & Aparelho auditivo & $\begin{array}{l}\text { Entre os dois principais aeroportos de } \\
\text { dois estados da região Sudeste } \\
\text { Aeroporto regional para um aeroporto } \\
\text { principal, ambos na região Sudeste; } \\
\text { e para outro aeroporto regional na } \\
\text { região Nordeste } \\
\text { P2 }\end{array}$ \\
Masculino & 19 & Superior complete & Perda bilateral severa & Não & $\begin{array}{l}\text { Aeroporto principal da região Sudeste } \\
\text { para aeroporto regional do Nordeste }\end{array}$ \\
\hline
\end{tabular}

\section{As experiências de viagem aérea dos passageiros com deficiência auditiva}

Em relação as barreiras que restringem a participação dos passageiros em referência no transporte aéreo, a partir da análise do questionário emergiram duas categorias temáticas: comunicação entre passageiros e trabalhadores das companhias aéreas e; orientação espacial e sinalização nos aeroportos. Além dessas, outras quatro categorias emergiram a partir dos dados obtidos por meio das observações e entrevistas de autoconfrontação: comunicação entre a equipe de solo e os comissários de bordo; sistema de entretenimento a bordo; limitação da autonomia do passageiro no aeroporto e; desrespeito às prioridades asseguradas por lei por passageiros sem deficiência.

Os facilitadores da viagem concentram-se em duas categorias que emergiram das entrevistas de autoconfrontação com os participantes: i) comunicação com trabalhadores que conhecem a língua de sinais e; ii) sistema de entretenimento a bordo que oferece legendas em seus conteúdos. Estratégias para lidar com as barreiras foram apontadas pelos respondentes do questionário.

\section{Comunicação entre passageiros e trabalhadores das companhias aéreas}

Os resultados do questionário evidenciaram que barreiras relacionadas a comunicação são encontradas em todas as fases da viagem e decorrem, especialmente, do não uso da língua de sinais no atendimento aos passageiros e despreparo dos funcionários das companhias aéreas nos aeroportos para o atendimento dos passageiros com deficiência auditiva - falam rápido e às vezes não olham diretamente para o passageiro, dificultando a leitura labial.

A partir da observação nas viagens realizadas junto aos passageiros e entrevistas de auto confrontação, 
Silva TNR, et al. Transporte aéreo e passageiros com deficiência auditiva. Rev Ter Ocup Univ São Paulo. 2020 jan.-dez.;31(1-3):69-77.

distinguiram-se três subcategorias: comunicação entre passageiros e funcionários das companhias aéreas nos aeroportos; comunicação entre passageiros e comissários de bordo e; comunicação entre passageiros e funcionários da companhia aérea na presença de outros passageiros ou acompanhantes ouvintes.

\section{Comunicação entre passageiros e funcionários das companhias aéreas nos aeroportos}

A partir da observação das experiências de viagens e das entrevistas com os participantes, constatou-se que uma das barreiras que dificultam a participação das pessoas com deficiência auditiva no transporte aéreo é o desconhecimento da língua de sinais pelos funcionários das companhias aéreas. No atendimento aos passageiros, especialmente no procedimento de check-in, é priorizada a linguagem oral ou escrita ou, em algumas ocasiões, a comunicação entre atendente e passageiro é impossibilitada.

Então, quando eu me aproximei a atendente que já estava sentada, fiz lingua de sinais, mas ela já estava escrevendo. Na hora que ela me pediu pra escrever eu fiquei me perguntando: e se fosse um surdo que não soubesse escrever, como seria a comunicação? Minha língua é sinais (P2 em um dos principais aeroportos da região sudeste)

Chegamos para fazer o check-in, ninguém sabia lingua de sinais, como ocorreu no aeroporto da capital. Ele simplesmente pegou meu documento (P2 em um aeroporto regional do Nordeste)

\section{Comunicação entre passageiros e funcionários das companhias aéreas nos voos}

As dificuldades com o atendimento, ocasionadas especialmente pela comunicação, foram relatadas pelos passageiros durante o percurso entre o balcão de check-in e o portão de embarque, como também durante o voo. Nessa fase da viagem as limitações relativas à comunicação prejudicaram a compreensão dos procedimentos de voo, inclusive de segurança, e de como solicitar auxílio à tripulação do voo.

[o voo] Foi bem, foi tranquilo, mas algo aconteceu que fiquei pensando era a questão da alimentação, se o lanche era pago ou não, e ai quando eu abordei a mulher perguntando se era gratuito a mulher ficou um pouco desesperada, não sabia como me responder e ai eu falei: “Ah tudo bem, pode passar”. Não peguei (o lanche) (P2).
As instruções de segurança de voo (briefing) são apresentadas e demonstradas antes da decolagem do avião pelos comissários de bordo. O briefing individual para o PNAE está previsto na Resolução da ANAC n ${ }^{\circ} 280 / 2013^{20}$, a qual enfatiza que o passageiro deve solicitar o procedimento. No entanto, em nenhum momento o passageiro é informado sobre essa alternativa e o relato dos participantes ilustra as consequências dessa situação:

De [aeroporto regional] para [aeroporto principal], eu sentei e um homem virou e simplesmente me cutucou falando que não podia, encostou no assento e eu não entendi o que ele tava falando, por que eu não posso deitar o meu assento? Por que eu tenho que ficar com ele assim? Ninguém sabia me explicar (P2).

No avião eu senti dificuldade, um pouco assim com as instruções (P1).

Além da dificuldade de comunicação devido às diferentes linguagens utilizadas, os passageiros revelaram situações em que permaneceram no voo sem qualquer tipo de assistência. Outro aspecto que prejudicou a compreensão das informações em voo é a qualidade do sistema de som.

$D e$ [aeroporto regional] para [aeroporto principal] não teve comunicação, não teve ajuda, não teve nada. Simplesmente fiquei sentado como uma estátua parado (P2)

Eu não entendi nada do que foi dito nas instruções. O som sai abafado, não entendi (Passageira P1 sobre o voo Rio de Janeiro - Belo Horizonte) (P1)

\section{Comunicação entre passageiros e funcionários das companhias aéreas na presença de outros passageiros ou acompanhantes ouvintes}

O passageiro $\mathrm{P} 2$ enfatizou ainda que na presença de outro passageiro ou um acompanhante ouvinte, a comunicação era estabelecida com este.

Pra te falar a verdade a gente já está até acostumado com esse processo [o pouco diálogo entre atendentes e a pessoa com deficiência auditiva], porque é uma coisa que sempre tem acontecido conosco. O surdo às vezes as pessoas olham como uma questão de caridade, uma questão de dó e ai quando tem um ouvinte perto eles sempre vão se relacionar com o ouvinte e acaba deixando a gente um pouco de lado (P3 em um dos principais aeroportos da região sudeste). 
Silva TNR, et al. Transporte aéreo e passageiros com deficiência auditiva. Rev Ter Ocup Univ São Paulo. 2020 jan.-dez.;31(1-3):69-77.

\section{Comunicação entre a equipe de solo da companhia aérea e comissários de bordo}

Também foram salientadas pelos passageiros as falhas na comunicação entre os trabalhadores das companhias aéreas que atuam no check-in e portões de embarque e os comissários de bordo. Dessa forma, comumente, os passageiros permanecem no voo sem serem percebidos pela tripulação que desconhece necessidades já comunicadas na compra da passagem e no aeroporto. Do mesmo modo, informações dos passageiros em voo, com frequência, não são repassadas aos aeroviários do aeroporto de destino ou desembarque para organização da assistência.

Então a moça que ia acompanhar a gente simplesmente sumiu na hora que a gente ia embarcar. Ela não estava lá, ela não acompanhou a gente até o avião. Também não avisou as aeromoças, comandante de voo. As aeromoças não estavam cientes que tinha embarcado dois deficientes (P1 embarcando em um dos principais aeroportos da região sudeste).

\section{Orientação espacial no aeroporto}

Em relação a orientação espacial no aeroporto, os respondentes do questionário salientaram que as informações visuais não favorecem a orientação nos terminais, por exemplo, para saber o local onde efetuar check-in ou retirar as bagagens após o desembarque. Além disso, destacaram que alterações nas informações de voo e chamadas para embarque são efetuadas, principalmente, por meio de avisos sonoros, o que impossibilita o entendimento da informação; a baixa qualidade do som nos avisos sonoros que dificultam o entendimento, especialmente, quando esse é o único formato utilizado nas comunicações do aeroporto; que o ambiente do aeroporto é confuso, tumultuado; painéis com informações de voo desatualizadas e; a falta legenda no idioma do país nas telas de informações ou de sistemas de entretenimento a bordo das aeronaves. Assim, é imprescindível que as informações sejam disponibilizadas em mais de um formato e que sejam em todos igualmente atualizadas.

A falta de meios auxiliares de orientação nos terminais, o que prejudica a orientação espacial dos aeroportos, também foi ressaltada pelos passageiros acompanhados nas viagens.

Dá pra entender por conta da proporção e o tamanho do aeroporto, que é minúsculo, mas informações não têm (P3 em um aeroporto regional do Nordeste).

\section{Sistema de entretenimento a bordo}

Os passageiros relataram nas entrevistas que é possível utilizar parcialmente o sistema, uma vez que apenas algumas aplicações ou conteúdos tinham legendas. Além disso, não havia janelas com exposição em língua de sinais.

\section{Limitação da autonomia do passageiro}

Outra barreira vivenciada e destacada por P2 ao longo das viagens foi a limitação da autonomia do passageiro no aeroporto devido ao modo como a assistência é oferecida pela companhia aérea. Ou seja, o passageiro deve permanecer em local determinado pela companhia e/ou atendente que realiza o acompanhamento enquanto aguarda o voo. Assim, é impedido seu envolvimento nas alternativas de entretenimento disponíveis nos aeroportos (lojas, livrarias, cafés, etc).

Teve uma mulher junto conosco, mas às vezes eu falava: "Ah eu quero ficar aqui, ou eu quero fazer uma outra coisa", ela [atendente-acompanhante] "Não". Estava o tempo todo junto com a gente ( $\mathrm{P} 2 \mathrm{em}$ um dos principais aeroportos da região Sudeste).

\section{Desrespeito às prioridades estabelecidas por lei por outros passageiros}

Por fim, a participante P1 destacou o desrespeito às prioridades estabelecidas por lei por parte de outros passageiros na organização das filas ao longo da viagem.

É na inspeção, na hora da inspeção, eu achei um absurdo a fila de deficiente, de grávida, de idoso. E tem muita gente que não se encaixava em nenhum dos quesitos ( $\mathrm{P} 1 \mathrm{em}$ um dos principais aeroportos da região Sudeste).

Além disso, um participante observou que a equipe da verificação de segurança não estava familiarizada com o dispositivo de implante coclear, o que tornou a passagem pela segurança um processo longo e embaraçoso.

\section{Facilitadores das viagens aéreas e estratégias dos passageiros}

Apesar de todas as dificuldades vivenciadas nas viagens aéreas devido à presença de barreiras nos aeroportos e nos voos, conforme apresentado, os passageiros também destacaram facilitadores nas viagens: comunicação com trabalhadores que têm conhecimento da língua de sinais e sistema de entretenimento a bordo com legenda nos conteúdos. 
Silva TNR, et al. Transporte aéreo e passageiros com deficiência auditiva. Rev Ter Ocup Univ São Paulo. 2020 jan.-dez.;31(1-3):69-77.

Comparando com as viagens anteriores, acho que essa foi melhor do que as anteriores. Porque uma das comissárias de bordo sabia a língua de sinais, então facilitou fazer algumas perguntas e ela me responder direto em línguas de sinais $(\mathrm{P} 2)$.

Foi uma sensação bacana porque a gente chegou, não tinha nada e nem ninguém pra nos ajudar, pra nos explicar nada e ai quando ela [funcionária da companhia aérea] perguntou se nós precisávamos de ajuda isso dá um certo alivio, se sente melhor ( $\mathrm{P} 3 \mathrm{em}$ um dos principais aeroportos da região sudeste).

Na televisão eu acompanhei algumas coisas devido a legenda só (P3).

No questionário os respondentes descrevam como eles lidam com as dificuldades nas viagens aéreas. As estratégias mencionadas envolvem principalmente os aspectos sociais do ambiente do transporte aéreo, tais como, 'solicitar ajuda aos atendentes da companhia aérea ou do aeroporto, aos comissários de bordo, aos outros passageiros ou ao acompanhante pessoal', 'comunicar-se por meio da escrita', 'avisar a companhia aérea sobre a deficiência e a necessidade de assistência', 'observar atentamente as informações dos painéis de voo e os demais passageiros', 'viajar somente acompanhado', 'solicitar ao comissário de bordo para falar diretamente para o passageiro', 'escolher assentos próximos aos comissários de bordo para tentar compreender os avisos de voo'e 'manter o aparelho auditivo ligado durante todo o voo'.

\section{DISCUSSÃO}

Os resultados apontaram as restrições na experiência de viagem dos passageiros com deficiência auditiva relacionadas a fatores contextuais que atuam como barreiras. Deve-se observar que, conforme descrito em outros estudos ${ }^{11,13,15}$, a falta de comunicação interpessoal, um dos componentes da acessibilidade $^{21}$, é a principal barreira para a participação de pessoas com deficiência auditiva em viagens aéreas, conforme destacado pelos participantes. Nesse sentido, destacou-se a comunicação entre passageiros e funcionários no transporte aéreo, uma vez que na maioria das situações estes últimos não conseguem utilizar a língua de sinais. Isso é ainda mais preocupante se considerarmos que as principais estratégias que esses passageiros utilizam para superar as dificuldades nas viagens aéreas e os facilitadores do processo envolvem a interação social, como mostraram os resultados do estudo.

Os participantes enfatizaram o desrespeito pelas formas distintas de comunicação por parte dos funcionários de companhias aéreas que prestam serviços aos passageiros com deficiência auditiva que não utilizam a comunicação verbal, por exemplo, quando o atendente insiste na linguagem oral ou no uso da linguagem escrita. Segundo Souza et al. ${ }^{14}$ a dificuldade de comunicação está na falta de conhecimento sobre as diferenças entre a língua de sinais e a comunicação verbal. A primeira é gesto-visual, sem flexão, gênero e escrita alfabética, enquanto a segunda é oral-auditiva e possui sintaxe e escrita alfabética. Portanto, a tentativa de comunicação escrita não é eficiente junto às pessoas surdas as quais podem não ser alfabetizadas, por exemplo, em Língua Portuguesa. Ademais, Moreira e Silva ${ }^{22}$ salientaram que a língua de sinais é a língua natural e base da identidade cultural da pessoa surda.

O estudo apresentou ainda ocasiões em que atendentes realizaram os procedimentos, por exemplo, para check-in, sem qualquer interação com o passageiro. Dessa forma, não é assegurado o acesso à informação, consequentemente, o passageiro não compreende o que foi realizado ou quais são os procedimentos a serem seguidos na viagem. Outra situação é quando a comunicação é realizada com um acompanhante ouvinte, excluindo o passageiro com deficiência auditiva do atendimento, o que também foi destacado em outros estudos que relataram as experiências de passageiros com diferentes tipos de deficiência ${ }^{8,15}$.

Outra barreira observada refere-se às falhas nos procedimentos das companhias aéreas em repassar informações aos atendentes que acompanharão o passageiro nas diferentes fases da viagem. Como exemplo, a chamada de embarque prioritário e o aviso de embarque aos passageiros P2 e P3 realizado por meio do alto-falante no aeroporto mesmo esses tendo comunicado sobre a deficiência no check-in. Esse evento contradiz o que está prescrito em resoluções do transporte aéreo ${ }^{20}$ e em outros documentos nacionais e internacionais ${ }^{4,6}$, que enfatizam a divulgação de informações em diferentes formatos e priorizam o embarque dos passageiros com deficiência.

A dificuldade de comunicação e as estratégias usadas reafirmam as barreiras atitudinais que contribuem para as restrições a participação dos passageiros com deficiência auditiva no transporte aéreo. Além do pouco conhecimento sobre a linguagem gesto-visual, e da ausência de intérpretes, em algumas situações observou-se a falta de esforços para comunicar-se por meio da expressão corporal ou mímica, priorizando-se a comunicação oral ou escrita. Essas atitudes desconsideram as potencialidades e singularidades de cada sujeito e a diversidade de formas de comunicar. Ademais, externalizam representações hegemônicas associadas a deficiência que buscam 'normalizar' o sujeito para permitir sua participação.

Diante das barreiras que se manifestam na interação social, a capacitação para atendimento adequado 
às pessoas com deficiência foi enfatizada em outros estudos $^{8-11,13,15}$. Faz-se necessário revisar os programas dos treinamentos oferecidos, bem como a periodicidade das atualizações realizadas, buscando construir oportunidades para experiências práticas que favoreçam os processos de aprendizagem. Para além da capacitação, Da Silva ${ }^{15}$ salientou que no transporte aéreo os funcionários que prestam assistência aos passageiros acumulam atividades $\mathrm{e}$, às vezes, estão em número insuficiente às demandas, o que inevitavelmente prejudica a qualidade dos atendimentos. Logo, analisar a experiência dos passageiros e promover ambientes que assegurem a participação de todos, requer também considerar os processos de trabalho que envolvem os funcionários das companhias aéreas e aeroportos.

Os passageiros participantes também relataram dificuldades em se orientar nos terminais do aeroporto e no entendimento dos procedimentos de segurança e/ou comunicação de eventos adversos durante os voos. A sinalização e as informações fornecidas nos aeroportos e nos voos estudados, muitas vezes, só estão disponíveis em um único formato ou em formatos que não são acessíveis a todos; portanto, eles não estão em conformidade com os regulamentos de acessibilidade para edifícios públicos. A informação é imprecisa nos aeroportos, até mesmo a sinalização para o balcão de informações. Esses resultados estão de acordo com os obtidos por Andrade et al. ${ }^{16} \mathrm{e}$ Da Silva ${ }^{15}$, que concluíram que a sinalização era inacessível para viajantes com deficiência auditiva.

Destacou-se ainda o entretenimento a bordo como uma barreira corroborando outros estudos ${ }^{11,15,17}$. Estes sistemas constituem-se como recursos que poderiam ser melhor aproveitados tanto para diversão quanto para a divulgação das informações de voo e procedimentos de segurança. As legendas, destacadas como facilitadoras, e as janelas com a interpretação dos conteúdos em língua de sinais podem ser incorporados em todos os recursos ou programas disponibilizados. Vale ressaltar que as limitações relacionadas ao uso dos sistemas de entretenimento a bordo foram enfatizadas sucintamente pelos participantes, o que pode estar relacionado ao curto tempo de duração dos voos realizados, a pouca experiência no transporte aéreo e a relevância das demais barreiras à participação nas viagens.

Outro questionamento que esse resultado provoca é se há uma baixa exigência ou expectativa das pessoas com deficiências em relação ao que é oferecido nos diferentes contextos sociais. Isso também foi evidenciado entre os facilitadores da participação nas viagens, com destaque para a presença de pessoas com algum conhecimento da língua de sinais ou apenas disponíveis para tentar estabelecer uma comunicação utilizando diferentes línguas. Ou seja, o mínimo que às vezes é proporcionado é percebido como suficiente para essas pessoas sentirem-se respeitadas e acolhidas em determinada situação, o que pode estar associado a vivência histórica de exclusão, privação de oportunidades e discriminação.

Tais experiências são ainda atuais, mesmo que, internacionalmente, reconhece-se o direito das pessoas com deficiências à participação social, o qual que deve ser assegurado não apenas nas políticas, mas em ações efetivas nos diversos contextos de vida. De acordo com Andrade ${ }^{7}$, os modos singulares de ser e viver devem ser respeitados, assegurando os mesmos direitos e oportunidades para todas as pessoas, assim como o respeito à dignidade humana, à igualdade e à liberdade pessoal.

O presente estudo, assim como outros, tem limitações, entre as quais destacam-se o número restrito de passageiros participantes e de voos realizados. Apesar do foco em um grupo específico de pessoas com deficiência, a escolha da deficiência auditiva foi pautada principalmente na carência de estudos sobre esse grupo no contexto do transporte aéreo. As perspectivas e as experiências dos passageiros foram consideradas no estudo e estes participantes contribuíram para a identificação dos problemas existentes.

\section{CONSIDERAÇÕES FINAIS}

No transporte aéreo os passageiros estão sujeitos a diversas situações estressantes, tais como atrasos de voos, distâncias dos aeroportos, ambientes aos quais estão pouco familiarizados, procedimentos necessários para a viagem, regras de bagagem, entre outros. Tais questões podem ser amplificadas por barreiras que tornam a experiência de passageiros com deficiência ainda mais desagradável e constrangedora. $\mathrm{O}$ estudo realizado permitiu aprofundar o entendimento sobre as experiências de passageiros com deficiência auditiva no transporte aéreo brasileiro e identificar as principais barreiras que restringem a participação desses ao longo de todas as fases das viagens, assim como, facilitadores.

Espera-se que o presente estudo contribua para melhorar os processos de inclusão, os dispositivos e procedimentos envolvendo aeroportos, companhias aéreas, fabricantes de aeronaves e equipamentos e agências reguladoras do transporte aéreo, bem como os treinamentos de pessoal para garantir assistência adequada ao público diversificado. Para tanto, um melhor conhecimento das atividades de trabalho também se faz necessário, construindo um entendimento global da problemática da acessibilidade na aviação civil. 
Silva TNR, et al. Transporte aéreo e passageiros com deficiência auditiva. Rev Ter Ocup Univ São Paulo. 2020 jan.-dez.;31(1-3):69-77.

Agradecimentos: Os autores agradecem o apoio da Embraer S/A, da Agência Nacional de Aviação Civil, Conselho Nacional de Desenvolvimento Científico e Tecnológico (Processo 426491/2016-5) e da Secretaria do Estado de São Paulo dos Direitos da Pessoa com Deficiência.

Participação dos autores: Todos os autores participaram do desenho do estudo, da elaboração e revisão do artigo. Da Silva TNR, Ribeiro LA, Silvestrini GA, Vidotti HGM e Figueiredo JP: realizaram as coletas e análises dos dados. Da Silva TNR: editou a versão final do artigo.

\section{REFERÊNCIAS}

1. World Health Organization, and World Bank. World report on disability. Geneva; 2011. Disponível em: https://www.who.int/ disabilities/world_report/2011/en/

2. Instituto Brasileiro de Geografia e Estatística (IBGE). Censo Demográfico 2010. Rio de Janeiro: IBGE; 2012. Disponível em: https://ww2.ibge.gov.br/home/estatistica/populacao/ censo2010/

3. Sampaio R, Luz MT. Human functioning and disability: exploring the scope of the World Health Organization's international classification. Cad Saúde Pública. 2009;25:475-83. doi: 10.1590/S0102-311X2009000300002.

4. United Nations. Convention on the Rights of Persons with Disabilities. New York; 2006. Available from: http://www. un.org/disabilities/documents/convention/convoptprot-e.pdf.

5. Brasil. Viver sem Limite - Plano Nacional dos Direitos da Pessoa com Deficiência. Brasília: SDHPR/ SNPD; 2013. Disponível em: http://www.pessoacomdeficiencia.gov.br.

6. Brasil. Lei no. 13146 - Lei Brasileira de Inclusão da Pessoa com Deficiência: Estatuto da Pessoa com Deficiência. Brasília; 2015. Disponível em: http://www.planalto.gov.br/ccivil_03/_ ato2015-2018/2015/lei/113146.htm.

7. Andrade JMP. Vulnerabilidade e vulneração, quando as pessoas com deficiência passam a ser questão de direitos humanos? Saúde e Direitos Humanos. 2009;6(6):29-43.

8. Poria Y, Reichel A, Brandt, Y. The flight experiences of people with disabilities: an exploratory study. J Travel Res. 2010;49(2):216-27. doi:10.1177/0047287509336477.

9. Darcy S. (Dis)Embodied air travel experiences: disability, discrimination and the effect of a discontinuous air travel chain. J Hosp Tour Manag. 2012;19:1-11. doi:10.1017/jht.2012.9.

10. Chang FC, Chen CF. Meeting the needs of disabled air passengers: factors that facilitate help from airlines and airports. Tour Manag. 2012;33:529-36. doi:10.1016/j. tourman.2011.06.002

11. Silva TNR, Guarda JBS, Silva LLG, Figueiredo JP, Menegon NL. Passengers with disabilities in the Brazilian air transport: different actors and similar perspectives. Gest Prod. 2017;24(1):136-47. doi:10.1590/0104-530x1681-15.

12. Davies A, Christie N. An exploratory study of the experiences of wheelchair users as aircraft passengers-implications for policy and practice. IATSS Res. 2017;41(2): 89-93. doi:10.1016/j.iatssr.2017.05.003.

13. Freeman I, Selmi N. French versus Canadian tourism: response to the disabled. J Travel Res. 2010;49(4):471-85. doi:10.1177/0047287509349268.

14. Souza MFNS, Araujo AMB, Sandes LFF, Freitas D, Souza NFNS, raujo ANS, et at.. Principais dificuldades e obstáculos enfrentados pela comunidade surda no acesso à saúde: uma revisão integrativa de literatura. Rev CEFAC. 2017;19(3): 395-405. doi:10.1590/1982-0216201719317116.

15. Silva TNR. Contradições e descontinuidades nos sistemas de atividade do transporte aéreo brasileiro: restrições às viagens $\mathrm{e}$ as estratégias de passageiros com deficiência, idosos e obesos [tese]. São Carlos: Universidade Federal de São Carlos; 2016.

16. Andrade IF, Sottoriva AM, Zanchin M, Rodeghiero Neto I. Análise das condições de orientação espacial de terminal de embarque aeroportuário sob o ponto de vista dos usuários. In: $15^{\circ}$ ERGODESIGN - Congresso Internacional de Ergonomia e Usabilidade de Interfaces Humanotecnologia, Recife, PE; 2015 p.212-23. 10.5151/15ergodesign-34-E002. doi: 10.5151/15ergodesign-34-E002.

17. Eghtesadi C, Goldberg L, Botkin B, O'Connel T. Accessible InFlight Entertainment Systems for Blind and Deaf Passengers. Ergon Des. 2012;20(3):7-13. doi:10.1177/1064804612444786.

18. Guérin F, Laville A, Daniellou F, Duraffourg J, Kerguelen A. Understanding and transforming work: the practice of ergonomics. Lyon: ANACT Network Editions; 2007

19. Minayo MCS. O desafio do conhecimento: pesquisa qualitativa em saúde. 14a ed. São Paulo: Hucitec; 2014.

20. Agência Nacional de Aviação Civil. Resolução no. 280: Procedimentos relativos à acessibilidade de passageiros com necessidade de assistência especial ao transporte aéreo e dá 
Silva TNR, et al. Transporte aéreo e passageiros com deficiência auditiva. Rev Ter Ocup Univ São Paulo. 2020 jan.-dez:;31(1-3):69-77.

outras providências. Brasília, DF: Diário Oficial da República Federativa do Brasil; 2013.

21. Dischinger M, Ely VHMB, Piardi SMDG. Promovendo acessibilidade espacial nos edifícios públicos: Programa de Acessibilidade às Pessoas com Deficiência ou Mobilidade
Reduzida nas Edificações de Uso Público. Florianópolis: Ministério Público de Santa Catarina; 2012.

22. Moreira CJ, Silva TV. Educação de surdos: Reflexões sobre as diferenças culturais e identitárias. Rev Cocar. 2013;7(13):50-8. 